Brit. Heart J., 1966, 28, 716.

CASE REPORTS

\title{
Patent Ductus Arteriosus in an Elderly Man
}

\author{
D. B. CALNE AND E. B. RAFTERY
}

From the Cardiac Department, St. Thomas' Hospital, London S.E.1

It is well known that a patent ductus arteriosus is commoner in women than in men (Wood, 1956), and longevity seems to be the prerogative of the woman. Fairley and Goodwin (1959) found that 5 per cent of their series of adults with this anomaly survived the age of 60 , but noted that they were all women. This is a report of a man aged 61 in whom a patent ductus arteriosus was diagnosed for the first time.

\section{Case Report}

The patient was a retired chemist in whom a diagnosis of "weak heart" was made at the age of 5. Despite this he led a full and active life, playing tournament tennis until the age of 58. At that time he was admitted to hospital with an attack of paroxysmal tachycardia which was controlled by large doses of quinidine. A loud systolic murmur was noted to be present in the pulmonary area but there was no diastolic murmur. He was admitted twice with similar attacks in the next three years, and the electrocardiograms showed a wide variety of arrhythmias. In 1961 a pulmonary diastolic murmur was heard for the first time. This increased in loudness over the course of the next three years while the systolic murmur became

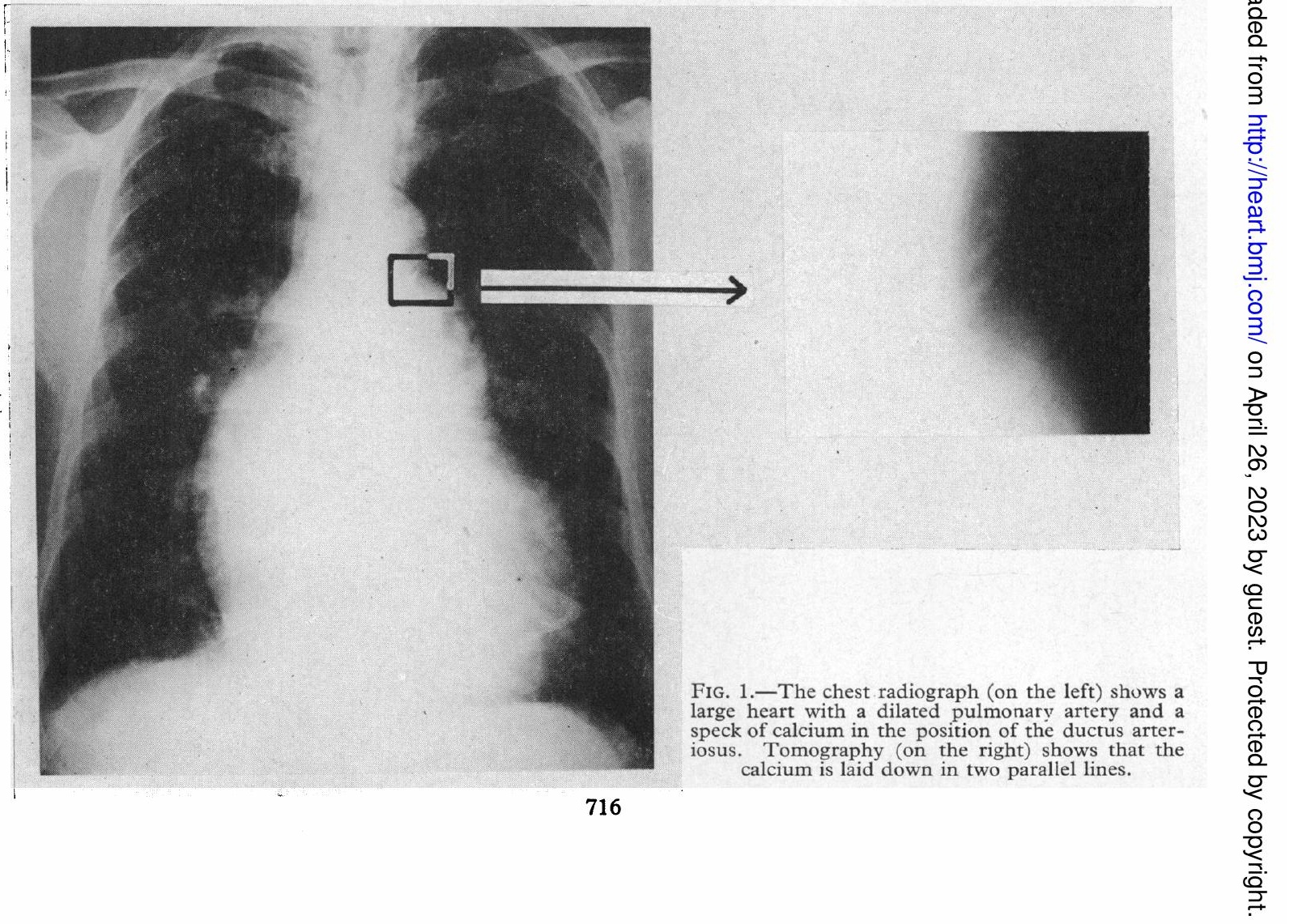


less prominent. He started to fibrillate in 1961, and at the same time he developed progressive shortness of breath on exertion.

On examination, his jugular venous pressure was raised $6 \mathrm{~cm}$. and the pulse was atrial fibrillation at 100 per minute. There was no peripheral œdema, and his blood pressure was $150 / 70 \mathrm{~mm} . \mathrm{Hg}$. The apex beat was both right and left ventricular in character, with a systolic thrill in the pulmonary area. There was a short systolic murmur in the pulmonary area. The pulmonary component of the second heart sound was accentuated, but moved normally with respiration. It was followed by a long early diastolic murmur which varied with respiration. The chest radiograph showed a large heart, with enlargement of the pulmonary artery and calcification in the arch of the aorta. Tomograms showed that the calcium was laid down in two parallel lines (Fig. 1). The electrocardiogram showed atrial fibrillation, with left bundle-branch block and left ventricular hypertrophy.

Cardiac catheterization was performed, and the catheter passed from the pulmonary artery to the aorta. The catheter was also passed through an interatrial communication to the left side of the heart. The pressure in the pulmonary artery was $50 / 22 \mathrm{~mm}$. $\mathrm{Hg}$, and the right ventricular pressure was $46 / 3 \mathrm{~mm}$. Hg. The mean right atrial pressure was $4 \mathrm{~mm}$. $\mathrm{Hg}$. and the mean left atrial pressure was $22 \mathrm{~mm}$. $\mathrm{Hg}$. Aortic pressure was $135 / 56$ $\mathrm{mm} . \mathrm{Hg}$. There was a step-up in oxygen saturation of 10 per cent between the superior vena cava and the right ventricle, with a further step-up of 7 per cent between the right ventricle and the pulmonary artery. Intra-

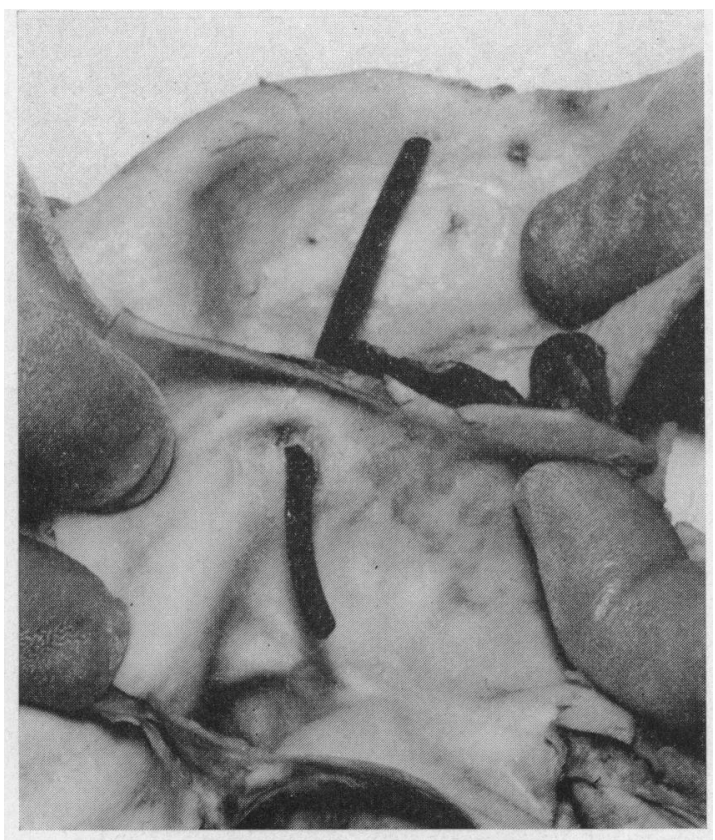

FIG. 2-The patent ductus arteriosus, seen from the pulmonary artery. Note how short it is, and how the opening appears at the bottom of a shallow depression. cardiac phonocardiograms clearly showed a diastolic murmur in the right ventricle.

From these data, a diagnosis was made of calcified patent ductus arteriosus with pulmonary incompetence and an interatrial communication. It was proposed to operate and close the patent ductus, but the patient died suddenly while awaiting admission.

The necropsy confirmed the clinical diagnosis (Fig. 2) and showed the interatrial communication to be a patent foramen ovale.

\section{Discussion}

The fact that women survive to a later age with uncomplicated patent ductus arteriosus suggests that men develop complications at an earlier age. Why this should be so is obscure, but it is possible that since the anomaly is so much more uncommon in men, late survivors are not often seen. It is clear that in this case the cause of death was related to the complex arrhythmias that the patient was exhibiting before he died; arrhythmias of this kind are not common with patent ductus arteriosus. The presentation, as a case of pulmonary incompetence, is very unusual and difficult to explain. The appearance of the diastolic murmur associated with loss of the systolic murmur suggested that pulmonary hypertension had developed. However, there was no evidence of pulmonary hypertension of this degree on catheterization.

The anatomy of the duct was typical in that it was very short and the aortic opening was at the bottom of a shallow depression in the sides of which calcium was deposited. This appearance has been reported in most cases of patent ductus, which have survived to adult life (Keys and Shapiro, 1943). This gave a characteristic appearance to the chest radiograph, which aroused the suspicion of a patent ductus, despite the paucity of clinical evidence before catheterization.

\section{Summary}

A case of calcified patent ductus arteriosus in a man of 61 is reported. The patient presented as a case of gross pulmonary incompetence. The reasons for greater longevity in women with this anomaly are discussed.

Our thanks are due to Dr. W. Medd and Dr. Evan Jones for permission to publish this case.

\section{References}

Fairley, G. Hamilton, and Goodwin, J. F. (1959). Patent ductus arteriosus in adult life. Brit. F. Dis. Chest, 53, 263.

Keys, A., and Shapiro, M. J. (1943). Patency of the ductus arteriosus in adults. Amer. Heart F., 25, 158.

Wood, P. (1956). Diseases of the Heart and Circulation, 2nd ed. Eyre and Spottiswoode :London. 